Hort, E. C., and Penfold, W. J. (1912). F. Hyg. (Lond.), 12, 361. Horvath, S. M., Radcliffe, C. E., Hutt, B. K., and Spurr, G. B. (1955). 7. appl. Physiol., 8, 145.

Hull, D., and Segall, M. M. (1965). 7. Physiol. (Lond.), 181, 449. Iampierto, P. F., Buskirk, E. R., Bass, D. E., and Welch, B. E. (1957). 7. appl. Physiol., 11, 349 .

Johnson, R. H., Smith, A. C., and Spalding, J. M. K. (1963). F. Physiol. (Lond.), 169, 584.

Kaiser, H. $\mathrm{K}$, and Woollner, L. (1965). Lancet, 1, 731.

Kaper, K., and Wood, W. B. (1962). F. exp. Med., 115, 27.

Kappas, A., Soybel, W., Fukushima, D. K., and Gallagher, T. F. (1959).

Trans. Ass. Amer. Physns, 72, 54.

Kerslake, D. M., and Cooper, K. E. (1950). Clin. Sci., 9, 31.

- (1958b). Ibid, 107, 291.

Knigge, K. M., and Bierman, S. M. (1958). Amer. F. Physiol., 192, 625 .

Ladell, W. S. S., Waterlow, J. C., and Hudson, M. F. (1944). Lancet, 2, 491.

Liebermeister, C. von (1875). Handbuch der Pathologie und Therapie des Fiebers. Vogel, Leipzig.

Loveless, A. H., and Maxwell, D. R. (1965). Brit. F. Pharmacol., 25, 158 .
Macpherson, R. K. (1959). Clin. Sci., 18, 281.

Magoun, H. W., Harrison, F., Brobeck, J. R., and Ranson, S. W. (1938). 7. Neurophysiol., 1, 101 .

Menkin, V. (1945). Arch. Path., 39, 28.

Nakayama, T., Hammel, H. T., Hardy, J. D., and Eisenman, J. S. (1963). Amer. 7. Physiol. 204, 1122.

Nielsen, B., and Nielsen, M. (1965a). Acta physiol. scand., 64, 314.

Nisen, B., (1965b). Ibid., 64, 323.

Nielsen, M. (1938). Skand. Arch. Physiol., 79, 193.

Nielsen, M. (1938). Skand. Arch. Physiol., 79, 193.

Pickering, G. W. (1932). Heart, 16, 115 .

Renbourn, E. T. (1960). 7. psychosom. Res., 4, 149.

Siebert, F. B. (1925). Amer. Y. Physiol., 71, 621.

Snell, E. S. (1954). F. Physiol. (Lond.), 125, 361.

- (1961). Clin. Sci., 21, 115 .

(1962). Ibid., 23,141.

Goodale, F., Wendt, F., and Cranston, W. I. (1957). Ibid., 16, 615.

Stern, R. (1892). Z. klin. Med., 20, 63.

Stern, R. (1892) Z. klin. Med., 20, 63. i, 428.

Tillor, G. F. (1964). Brit. med. (1965). Amer. 7. Physiol., 208, 703.

Wendt, F., Snell, E. S., Goodale, F. and Cranston W. I. (1956). Clin. Sci. 15, 485 .

\title{
Chemotherapy of Hodgkin's Disease with Cyclophosphamide, Vinblastine, and Procarbazine
}

\author{
G. HAMILTON FAIRLEY,* M.A., D.M., M.R.C.P. ; M. J. L. PATTERSON,*† M.B., M.R.C.P. \\ Sir RONALD BODLEY SCOTT, K.C.V.o., M.A., D.M., F.R.C.P.
}

Brit. med. F., 1966, 2, 75-78

Radiotherapy is undoubtedly the best treatment for localized Hodgkin's disease, and there have now been very encouraging reports from several centres (Peters and Middlemiss, 1958; Kaplan, 1962 ; Easson and Russell, 1963 ; Cohen et al., 1964 ; Fayos et al., 1965). However, it is not always possible to use radiotherapy, because the disease may be too disseminated or there may be a recurrence in an area which has already been heavily irradiated. In these circumstances chemotherapy is indicated.

Of all malignant diseases those arising in lymphoreticular tissue respond most consistently and often dramatically to chemotherapy, and this applies particularly to Hodgkin's disease. In the last few years more agents have become available, and it has been our practice at St. Bartholomew's Hospital, when the need for chemotherapy arises, to treat patients initially with some form of nitrogen mustard, usually cyclophosphamide (Endoxana), and to continue this until the disease is no longer responding; vinblastine sulphate (Velbe) is then used until it becomes ineffective, and this is followed by a methylhydrazine derivative, procarbazine hydrochloride (Natulan). We have used the drugs in this way because it is the order in which they became available, but it has been suggested by Todd (1965a) that the order is unrelated to their therapeutic effects.

The purpose of this communication is to review our results, using these three compounds consecutively, and discuss whether better results might be obtained by using them in a different order or concurrently.

\section{Material and Methods}

Only patients with classical Hodgkin's disease (Hodgkin's granuloma) have been included ; those with paragranuloma and so-called Hodgkin's sarcoma have been excluded.

* St. Bartholomew's Hospital, London.

$t$ In receipt of a research grant for the investigation of Hodgkin's disease from Mr. C. Coombs.
Since radiotherapy is the treatment of choice in localized Hodgkin's disease, many of the patients had received radiotherapy before being given chemotherapy.

Because of the difficulty in assessing the efficacy of any form of treatment in a disease like Hodgkin's disease, with such a variable course, only the initial response to each agent will be analysed. Subjective improvement was assessed by the symptoms of malaise, pruritus, and pain when this could definitely be attributed to the disease, and objective improvement by the abolition of fever, a gain in weight in those patients in whom recent weight loss had occurred, and a reduction in the size of the lymph nodes and the spleen. In assessing the overall results, the response to treatment was considered to be " beneficial" only if there was improvement in one of the objective criteria for at least one month. No patient was recorded as benefiting if there was only an improvement in symptoms.

\section{Results}

\section{Treatment with Cyclophosphamide}

Sixty-two patients with Hodgkin's disease have been treated with cyclophosphamide for a variable period up to three years. Of these, 54 had previously received some other form of treatment-that is, radiotherapy, mustine hydrochloride, chlorambucil, or corticosteroids-and in only eight was cyclophosphamide the first form of treatment used.

Many patients inititally received the drug by intravenous injection, $2 \mathrm{~g}$. being given over a period of 10 days. Maintenance treatment was continued by oral administration, starting with $150 \mathrm{mg}$. daily and reducing this dose or stopping the drug if severe leucopenia or any other side-effect developed.

The overall results are shown in Table I. Cyclophosphamide was beneficial-that is, it produced objective improvement lasting at least one month-in 43 patients (69\%), 6 patients $(10 \%)$ were unaffected, and in 13 patients $(21 \%)$ the treatment failed. In these 13 treatment failures there was clinical 
deterioration in nine while the patients were receiving the drug, and the treatment was abandoned in four, because of nausea and vomiting in two, profound leucopenia in one, and refusal to take tablets in another.

TABLE I.-Initial Results of Treatment with Cyclophosphamide in 62 Patients with Hodgkin's Disease

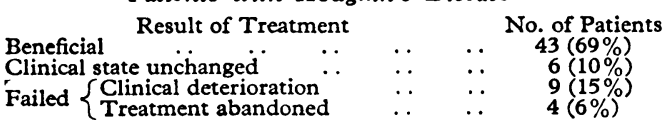

Table II shows the effect of cyclophosphamide on various symptoms and signs in 58 patients with Hodgkin's disease (the four in whom treatment was abandoned having been omitted). Twenty-nine complained of malaise ; 20 (approximately $70 \%$ ) felt better, three were unaffected, and six were worse. Pruritus was really troublesome in eight, of whom six $(75 \%)$ were improved. Pain, which occurred chiefly with bone lesions and mediastinal and intra-abdominal lymphadenopathy, and which was sometimes related to the taking of alcohol, was relieved in 10 out of 11 patients.

TABLB II.-Analysis of the Effect of Cyclophosphamide on Various Symptoms and Signs in 58 Patients with Hodgkin's Disease

\begin{tabular}{|c|c|c|c|c|c|}
\hline \multicolumn{2}{|c|}{$\begin{array}{l}\text { Manifestations of } \\
\text { Disease }\end{array}$} & $\begin{array}{c}\text { No. of } \\
\text { Patients }\end{array}$ & Better & Unchanged & Worse \\
\hline Subjective & $\left\{\begin{array}{l}\text { Malaise .. } \\
\text { Pruritus } \\
\text { Pain }\end{array}\right.$ & $\begin{array}{r}29 \\
8 \\
11\end{array}$ & $\begin{array}{r}20 \\
6 \\
10\end{array}$ & $\begin{array}{r}3 \\
2 \\
-\end{array}$ & $\frac{6}{1}$ \\
\hline \multirow{2}{*}{ Objective } & \multirow{2}{*}{$\begin{array}{l}\text { Fever } \\
\text { Weight loss } \\
\text { Enlargement of } \\
\text { lymph nodes } \\
\text { and spleen }\end{array}$} & $\begin{array}{l}14 \\
19\end{array}$ & $\begin{array}{l}13 \\
13\end{array}$ & $\frac{1}{5}$ & $\overline{1}$ \\
\hline & & 49 & 33 & 7 & 9 \\
\hline
\end{tabular}

Fourteen patients had fever which was observed in hospital, and in 13 the fever abated after treatment with cyclophosphamide; this is probably an unrealistic result, as the fever is usually undulant or relapsing in type and tends to remit spontaneously. Weight loss was significant in 19 patients -13 (approximately 70\%) gained weight with treatment, five were unchanged, and one continued to lose. In 49 patients there was significant enlargement of superficial lymph nodes or the spleen when treatment with cyclophosphamide was started; there was a reduction in size in $33(67 \%)$, but no change in 7 , and progressive enlargement in 9.

\section{Treatment with Vinblastine Sulphate}

Twenty-eight patients who had failed to respond or were no longer responding to cyclophosphamide were treated with vinblastine. This was given by intravenous injection in a dose of 0.1 to $0.2 \mathrm{mg}$. $/ \mathrm{kg}$. weekly, the usual dose for adults being $10 \mathrm{mg}$./week. The results were analysed in exactly the same way as for cyclophosphamide.

Table III shows the overall results. Vinblastine had a beneficial effect in 18 patients $(65 \%)$, two $(7 \%)$ were unaffected, and in eight $(28 \%)$ the treatment failed. Of these eight failures there was clinical deterioration in four while the patients were receiving the drug, and the treatment was abandoned in four, because of nausea and vomiting in one, severe pain in enlarged nodes on the day following injection in one, and abdominal pain, probably due to slight overdose, in two.

TABI.E III.-Initial Results of Treatment with Vinblastine in 28 Patients with Hodgkin's Disease

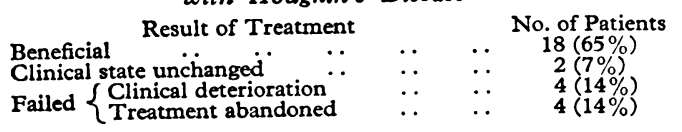

Table IV shows the effect of the symptoms and signs in 24 patients (the four in whom treatment was abandoned having been omitted). The results are similar to those seen with cyclophosphamide.
TABLE IV.-Analysis of the Effect of Vinblastine on Various Symptoms and Signs in 24 Patients with Hodgkin's Disease

\begin{tabular}{|c|c|c|c|c|c|}
\hline \multicolumn{2}{|c|}{$\begin{array}{c}\text { Manifestations of } \\
\text { Disease }\end{array}$} & $\begin{array}{l}\text { No. of } \\
\text { Patients }\end{array}$ & Better & Unchanged & Worse \\
\hline Subjective & $\left\{\begin{array}{l}\text { Malaise ... } \\
\text { Pruritus } \\
\text { Pain } \ldots\end{array}\right.$ & $\begin{array}{r}11 \\
3 \\
3\end{array}$ & $\begin{array}{l}6 \\
2 \\
2\end{array}$ & $\begin{array}{l}3 \\
1 \\
1\end{array}$ & $\underline{2}$ \\
\hline Objective & $\left\{\begin{array}{l}\text { Fever . } \\
\text { Weight loss } \\
\text { Enlargement of } \\
\text { lymph nodes } \\
\text { and spleen }\end{array}\right.$. & $\begin{array}{l}11 \\
12\end{array}$ & $\begin{array}{l}7 \\
8\end{array}$ & $\begin{array}{l}4 \\
2\end{array}$ & $\overline{2}$ \\
\hline
\end{tabular}

\section{Treatment with Procarbazine}

Seventeen patients who were no longer responding to either cyclophosphamide or vinblastine were treated with procarbazine. This was given orally, starting with $50 \mathrm{mg}$. daily after meals and slowly increasing to $250 \mathrm{mg}$. daily. Either pyridoxine or perphenazine (Fentazin) was used to control nausea and vomiting.

Table $\mathrm{V}$ shows the overall results. Procarbazine was beneficial in 10 patients $(59 \%)$, two $(12 \%)$ were unaffected, and in five $(29 \%)$ the treatment failed. In these five treatment failures there was clinical deterioration in two while the patients were receiving the drug, and the treatment was abandoned in three because of nausea and vomiting.

TABLe V.-Initial Results of Treatment with Procarbazine in 17 Patients
with Hodgkin's
Disease
Result of Treatment

Table VI shows the effect on the symptoms and signs in 14 patients (the three in whom treatment was abandoned having been omitted). The results are similar to those seen with cyclophosphamide and vinblastine.

TABLB VI.-Analysis of the Effect of Procarbazine on Various Symptoms and Signs in 14 Patients with Hodgkin's Disease

\begin{tabular}{|c|c|c|c|c|c|}
\hline \multicolumn{2}{|c|}{$\begin{array}{c}\text { Manifestations of } \\
\text { Disease }\end{array}$} & $\begin{array}{l}\text { No. of } \\
\text { Patients }\end{array}$ & Better & Unchanged & Worse \\
\hline Subjective & $\left\{\begin{array}{l}\text { Malaise .. } \\
\text { Pruritus } \\
\text { Pain } \ldots\end{array}\right.$ & $\begin{array}{l}6 \\
3 \\
3\end{array}$ & $\begin{array}{l}2 \\
1 \\
3\end{array}$ & $\begin{array}{r}3 \\
2 \\
-\end{array}$ & $\underline{1}$ \\
\hline Objective & $\left\{\begin{array}{l}\text { Fever } \\
\text { Weight loss } \\
\text { Enlargement of } \\
\text { lymph nodes } \\
\text { and spleen }\end{array}\right.$ & $\begin{array}{r}8 \\
5 \\
12\end{array}$ & $\begin{array}{l}5 \\
3\end{array}$ & $\begin{array}{l}3 \\
1\end{array}$ & $\overline{1}$ \\
\hline
\end{tabular}

\section{Toxic Effects}

The most troublesome and most common side-effects of cyclophosphamide was alopecia, which was readily corrected after the drug was stopped. The white-cell count and particularly the mononuclear cells were used as a therapeutic index and were therefore constantly depressed, but the platelets and haemoglobin were usually well maintained throughout the use of this drug. Some patients developed mild gastro-intestinal disturbances, with nausea, vomiting, or diarrhoea, and two patients suffered from a severe haemorrhagic cystitis which required a complete cessation of the drug. Both these patients had been treated with cyclophosphamide for over three years, and had previously had irradiation, which could have involved the bladder. The app arances on cystoscopy were similar to those of irradiation cystitis, and it is possible that both radiotherapy and cyclophosphamide could have contributed to the condition, though there is no doubt that haemorrhagic cystitis occurs in patients receiving cyclophosphamide who have not been irradiated.

Treatment with vinblastine commonly caused leucopenia and did not seem to be dose-dependent, since one patient developed 
a sustained depression of the white-cell count after one injection of $6 \mathrm{mg}$. only; the haemoglobin and platelet levels were not affected by the dose used. Two patients developed severe abdominal pain and one had paralytic ileus with distension of the small gut and colon after a more intensive course of administration than subsequently became our routine. Peripheral neuropathy is a well-recognized complication which was seen in two patients; in one this occurred as a complication shortly before death, and failed to improve when the drug was stopped; in the other the signs improved slowly after the treatment was abandoned but it took five months for the tendon reflexes to return to normal. Epilation was not a troublesome effect of this drug.

In those patients who received procarbazine we found little in the way of troublesome side-effects apart from nausea and vomiting, which was usually controlled with either pyridoxine or perphenazine, though it led to the abandonment of treatment in three patients. The blood was examined frequently, but neither leucopenia nor thrombocytopenia was a problem in the dose we used, though, as with all cytotoxic drugs, these may occur. Only one patient, a man, noticed excessive loss of hair.

\section{Discussion}

Cyclophosphamide, like other forms of nitrogen mustard, is an accepted agent in the treatment of Hodgkin's disease, and our results are similar to those of other workers (Bethell et al., 1960 ; Matthias et al., 1960 ; Rundles et al., 1962 ; Fairley and Simister, 1964).

It has the great advantage that it can be given intravenously, into serous cavities, or orally, though its action even when injected is not as rapid as that of mustine hydrochloride. It can, however, be given for long periods of time, and we have several patients who have been taking it for three years without ill effects. Its disadvantages include loss of hair, depression of the leucocyte and platelet counts, and occasionally anorexia, nausea, vomiting, and haemorrhagic cystitis. These side-effects usually disappear rapidly when the drug is stopped, and are relatively infrequent in the dosage required to control this disease.

Vinblastine is also a useful agent in the treatment of Hodgkin's disease. Hodes et al. (1960) reported a beneficial effect in patients with Hodgkin's disease, and noted the side-effects of epilation and paraesthesiae. Since then there have been many reports in which between $36 \%$ and $67 \%$ of the patients have responded (Hodes et al., 1960 ; Hill and Loeb, 1961 ; Armstrong et al., 1962 ; Frost et al., 1962 ; Mathé et al., 1962 ; Wright et al., 1963 ; Bleehen and Jelliffe, 1965). Our results support these reports, with $65 \%$ of the patients benefiting.

Bleehen and Jelliffe (1965) comment that a good remission occurred more often in those patients who had responded previously to other agents, and a response was much less likely when the disease had proved refractory to treatment with other drugs. Of the 18 patients in this series who benefited from treatment with vinblastine, only four had previously failed to respond to cyclophosphamide. Of the six patients who either failed to benefit from vinblastine or actually deteriorated while on the drug three had previously responded to cyclophosphamide, two had failed to respond, and one could not take the drug because of vomiting.

Leucopenia is an established side-effect of treatment with vinblastine and occurred frequently, but thrombocytopenia was not a problem in our patients nor in other series (Marsden, 1963 ; Newall and Pringle, 1965). The most serious side-effect of vinblastine is that it is neurotoxic. Apart from the symptoms and signs of a peripheral neuropathy, a form of paralytic ileus may occur, with severe abdominal pain, distension of the colon and small gut, and constipation.
It is important that this complication should be recognized, as it may save unnecessary surgery (Bleehen and Jelliffe, 1965), though in one of our cases a temporary caecostomy was necessary to deflate the large bowel. We have not seen this complication in patients receiving vinblastine once a week, and the three patients in whom it developed had all been given injections at more frequent intervals. Similar results were reported by Frost et al. (1962).

We would recommend that vinblastine should not be given more than once a week in the treatment of Hodgkin's disease. We found that when treatment with vinblastine was stopped for any reason many of the patients rapidly relapsed and were sometimes resistant to further injections of vinblastine; we therefore favour maintenance treatment with weekly injections rather than courses, though Bleehen and Jelliffe (1965) recommend monthly injections for maintenance.

Procarbazine is the newest compound to be used in Hodgkin's disease, and there is no doubt that it is beneficial. Mathe et al. (1963) reported improvement in $68 \%$ of patients, and Todd $(1965 \mathrm{~b})$ in $62 \%$. Other workers have reported similar results (Dawson, 1965 ; Jelliffe et al., 1965 ; Newton, 1965 ; HopeStone, 1965 ; Todd, 1965a, 1965b). In this series $59 \%$ responded, a figure that might have been higher had the patients been treated with the drug earlier in the course of their disease.

The only side-effects we observed were nausea and vomiting. which led to treatment with procarbazine being abandoned in three patients. In the remainder these symptoms either did not occur or were readily corrected by perphenazine or pyridoxine.

Patients were more likely to respond to procarbazine if they had previously benefited from cyclophosphamide and vinblastine. Of the 10 patients who responded to procarbazine seven had previously responded to both the other drugs, two had failed to respond to cyclophosphamide, and one to vinblastine. Of the four patients who either failed to benefit from procarbazine or deteriorated while on the drug only one had previously responded to both cyclophosphamide and vinblastine, one had previously failed to respond to either of these drugs, one had responded to vinblastine but not to cyclophosphamide, and one to cyclophosphamide but not to vinblastine.

There can be no doubt that cyclophosphamide, vinblastine, and procarbazine are all valuable drugs in the treatment of Hodgkin's disease, and in the way in which we have used them cyclophosphamide improved $69 \%$ of the patients, vinblastine $65 \%$, and procarbazine $59 \%$. This minor difference is probably not significant because of the small number of patients and the order in which the drugs have been given, procarbazine being given much later in the disease than cyclophosphamide.

We chose to use these compounds in this order because it seemed reasonable to employ established agents before trying newer drugs. However, there is no proof that the sequential use of chemotherapeutic drugs is the right treatment for Hodgkin's disease, and, even if it were, the best order in which to use these agents is unkown. To determine this we have now embarked on a trial varying the order. It is possible that using drugs concurrently rather than consecutively might be more effective, and Lacher and Durant (1965) have reported improvement in $73 \%$ of patients treated with a combination of chlorambucil and vinblastine.

\section{Summary and Conclusions}

The results of treating generalized Hodgkin's disease with cyclophosphamide followed by vinblastine and then procarbazine are described. With cyclophosphamide $69 \%$ were improved, whereas improvement occurred in $65 \%$ with vinblastine and in $59 \%$ with procarbazine.

The toxic effects of these drugs are discussed, with particular emphasis on abdominal pain and paralytic ileus in patients overtreated with vinblastine. 
Each of these agents is of benefit in the management of advanced Hodgkin's disease, though the order in which they should be used has not yet been established, nor have the results of treatment with combinations of these agents been adequately explored.

We wish to thank Dr. John Marks, of Roche Products Ltd., for generous supplies of procarbazine (Natulan).

\section{REFERENCES}

Armstrong, J. G., Dyke, R. W., Fouts, P. J., and Gahimer, J. E. (1962). Cancer Chemother. Rep., 18, 49.

Bethell, F. H., Louis, J., Robbins, A., Donnelly, W. J., Dessel, B. H., Battle, J. D., Pisciotta, A. V., Will, J., and Clifford, G. O. (1960). Ibid., 8, 112 .

Bleehen, N. M., and Jelliffe, A. M. (1965). Brit. F. Cancer, 19, 268.

Cohen, B. M., Smetana, H. F., and Miller, R. W. (1964). Cancer (Philad.), 17, 856

Dawson $W$. B. (1965). Natulan (Ibenzmethyzin), edited by A. A. Jelliffe and J. Marks, p. 31. Wright, Bristol. Easson, E. C., and Russell, M. H. (1963). Brit. med. F., 1, 1704. phamide. Wright, Bristol.

Fayos, J., Hendrix, R., Macdonald, V., and Lampe, I. (1965). Amor. F. Roentgenol., 93, 557.
Frost, J. W., Goldwein, M. I., and Bryan, J. A. (1962). Ann. intern. Med., 56, 854 .

Hill, J. M., and Loeb, E. (1961). Cancer Chemother. Rep., 15, 41.

Hodes, M. E., Rohn, R. J., and Bond, W. H. (1960). Cancer Res., 20, 1041.

Hope-Stone, H. F. (1965). Natulan (Ibenzmethyzin) edited by A. M. Jelliffe and J. Marks, p. 15. Wright, Bristol.

Jelliffe, A. M., Bleehen, N. M., and Fenner, M. L. (1965). Ibid., p. 35. Kaplan, H. S. (1962). Radiology, 78, 553.

Lacher, M. J., and Durant, J. R. (1965). Ann. intern. Med., 62, 468.

Marsden, J. A. (1963). Med. F. Aust., 2, 100.

Mathé, G., Berumen, L., Schweisguth, O., Brule, G., Schneider, M. Cattan, A., Amiel, J. L., and Schwarzenberg, L. (1963). Lancet, 2, 1077 .

- Schweisguth, O., Brule, G., Amiel, J. L., Cattan, A., Thomas, M., and Zamet, P. (1962). Presse méd., 70, 1349.

Matthias, J. Q., Misiewicz, J. J., and Scott, R. B. (1960). Brit. med. F., 2, 1837.

Newall, J., and Pringle, J. F. (1965). Scot. med. F., 10, 288.

Newton, K. A. (1965). Natulan (Ibenzmethyzin), edited by A. M. Jelliffe and J. Marks, p. 26. Wright, Bristol.

Peters, M. V., and Middlemiss, K. C. H. (1958). Amer. 7. Roentgenol., 79, 114 .

Rundles, R. W., Laszlo, J., Garrison, F. E., jun., and Hobson, J. B. (1962). Cancer Chemother. Rep., 16, 407.

Todd, I. D. H. (1965a). Brit. med. F., 1, 628.

- (1965b). Natulan (Ibenzmethyzin), edited by A. M. Jelliffe and J. Marks, p. 20. Wright, Bristol.

Wright, T. L., Hurley, J., Korst, D. R., Monto, R. W., Rehn, R. J., Will, J. J., and Louis, J. (1963). Cancer Res., 23, i69.

\title{
Iron Absorption in Idiopathic Haemochromatosis before, during, and after Venesection Therapy
}

\author{
ROGER WILLIAMS, ${ }^{*}$ M.D., M.R.C.P. ; F. MANENTI, † M.D. ; H. S. WILLIAMS, $\ddagger$ M.SC., F.INST.P. \\ C. S. PITCHER, $\S$ D.M., M.C.PATH.
}

Brit. med. F., 1966, 2, 78-81

The aetiology of idiopathic haemochromatosis is disputed. Sheldon's (1935) postulate that the basic defect is an inborn error of metabolism causing increased iron absorption was largely based on the description of familial cases. Subsequent experience has shown that these are rare, though recent surveys by Williams et al. $(1962,1965)$ have revealed a high incidence of minor clinical signs, hepatic siderosis, and increased iron absorption in the immediate relatives. MacDonald (1964), however, impressed by the frequent clinical association of haemochromatosis with alcoholism, postulates that the disorder is acquired. In his view iron absorption is normal and the excess body iron results from the high iron content of certain alcoholic drinks. The cirrhosis is unrelated to the iron deposition and results from the coincidence of further environmental factors such as malnutrition, alcoholism, or previous viral hepatitis.

To date there have been relatively few measurements of iron absorption in haemochromatosis. The results are conflicting, and it has been suggested that absorption may be depressed by the time of presentation as a result of saturation of the iron stores. A few studies have shown increased absorption after venesection therapy (Peterson and Ettinger, 1953 ; Chodos et al., 1957 ; Pirzio-Biroli et al., 1958). This question is also important therapeutically in relation to the use and value of venesection therapy in the removal of the excess tissue-iron

\footnotetext{
* Consultant Physician, Department of Gastroenterology, Southampton General Hospital, Southampton. Formerly Lecturer in Medicine, College Hospital, London.

+ British Council Scholar.

† Brinish Council Scholar.

† Principal Hospital Physicist, Royal Free Hospital, London. Hospital, London.
}

and its subsequent maintenance at a normal level. For these reasons we have measured iron absorption serially at various intervals before, during, and after treatment, and in this paper report the results of 37 measurements in 19 male patients with idiopathic haemochromatosis. In a number of patients examined after completion of venesection therapy the plasma iron turnover was also measured.

\section{Material and Methods}

At the time of presentation all the patients had shown abnormal skin pigmentation and hepatomegaly. Diabetes or impaired carbohydrate tolerance was present in 12 and hypogonadism in 10. With one exception (Case 12) the diagnosis had been confirmed by liver biopsy, this showing both cirrhosis and marked iron deposition (grade 4 of Scheuer et al., 1962). The serum iron level varied, but all had a percentage saturation of the total iron-binding capacity of greater than $60 \%$. Cases $2,3,12,17$, and 19 gave a history of excessive alcohol consumption over a number of years before presentation. Beer and spirits were the main drinks consumed, with the exception of the one (Case 2) who had drunk mainly wine. Cases 2, 4, 8, 9, $10,13,15,17$, and 19 correspond to propositi in families $\mathrm{N}, \mathrm{U}$, $\mathrm{R}, \mathrm{S}, \mathrm{L}, \mathrm{P}, \mathrm{E}, \mathrm{F}$, and $\mathrm{O}$ in the previous reports of Williams et al. $(1962,1965)$.

The serum iron and total iron-binding capacity were estimated by Ramsay's (1957) method, 2, 2' 2" tripyridyl being used as the colour reagent. The blood was taken in the morning after an overnight fast. Plasma iron turnover was determined according to standard techniques (Dacie and Lewis, 1963). 